\title{
Simulation of Dynamics Behaviors for Shipping Equipment Support with System Dynamics Analysis Approach
}

\author{
Yang Song, Jian-hua Yang \\ Beïing University of ScienceぬTechnology (China) \\ leowonder@163.com,vangjh@ustb.edu.cn
}

Received: December 2014

Accepted: April 2015

\section{Abstract:}

Purpose: This paper mainly focuses on the exactly and precisely supply of carrying spare parts problem which has a crucial impact on supporting work and improving the performance of equipment. Spare parts support has been the crux work that will be limited by allocation of spare parts and input support cost. Reasonable support strategy may subserve the high efficiency of available resources allocation and supporting the equipment in normal operational status. The purpose of this paper is to propose a dynamics model of spare parts support process based on considering the interaction of multiple factors, and explore the regulation of dynamics behavior in the system. Further, findings indicate that it is more helpful to achieve the optimization strategy than to cut inventory, results of the former suggest that improve on the effect of support so that will enhance the relevant support parameters of equipment.

Design/methodology/approach: Consider the feedback relationship among some important factors of support that involves support cost, support time and maintenance ability. System dynamics theory is adopted to propose a dynamics model of spare parts support process, on the analysis of multiple factors and casual relationship to find some major ones which have crucial impact on spare parts support. Spare parts support cost and availability was regarded as the control objective, moreover, adjust the control paramours and improve the effect of cannibalization and lateral supply scheduling strategy for spares support. 
Findings: The factors of spare parts supply, demand and maintenance have relationship of control feedback, and adjust the value of some crucial factors can reduce the support cost and improve the availability value. The main finding is that adopting cannibalization strategy under condition of available materials can relieve the mission and operational availability decline caused by shortage of spare parts. Combining the lateral supply and cannibalization strategy can reduce the inventory of warship carrying spare parts.

Practical implications: By controlling the value of key factors regarding aspect of spare parts supply, logistics and maintenance planning. Decision makers can have a visualization guideline to make the adjustment of support strategy, and can achieve better management of equipment and spare parts.

Originality/value: This paper proposes a dynamics model and focuses on exploring the dynamics behavior of the support system that could help in improving the ability of warship equipment to make supply support strategy easily. It can provide visualization guideline for decision maker in the enterprise.

Keywords: system dynamics, availability, lateral transshipment policy, cannibalization

\section{Introduction}

Spare parts are the magnitude material base that can sustain the normal operating state for the equipment support. The all-in support cost comprise a large proportion of the whole life cycle of warship equipment, which can avoid the shortage of funds and spare parts, consequently, it is of great importance to make rational allocation of spare parts for accurately and timely equipment support work. During the mission time at sea, warship equipment usually faces a problem that is hard to get materials supplies, when warship equipment is in the malfunction condition or getting normal maintenance. The performance needs to restore through the voyage repair, and the materials are required by maintenance which could be provided by the warship carrying spare parts. Shortage of spare parts will influence maintenance work, moreover, that will reduce the level of equipment availability; If the warships carried a large number of spare parts to ensure the equipment that can run in a good condition, whether the quantity of spares needs overabundance is a highly debatable problem, however, the overabundance of spares will occupy a large amount of money of enterprise and cause waste of warship storage space. How to meditate that under multiple constraints such as the support cost, warship space, warship repair ability and so on. It is no exaggeration to say that reasonably allocation of spare parts to get the biggest warship support capability has become hot issues for the research of equipment support. 
In the application field of spare parts management theory which has attracted many experts and scholars at home and abroad, METRIC model (Sherbrooke, 1968) is the classical model in the field of repairable spare parts supply security, provides a theoretical basis for the spare parts to ensure optimal allocation. Because the model has some defects in scope of application and calculation precision, and then the other researchers proposed the improved model, such as MOD - METRIC model (Muckstadt, 1973), VARI - METRIC model (Hillestad, 1982), DYNA METRIC model (Sherbrooke, 1986). The VARI - METRIC model improved the original METRIC model in the multi-level security for the problem of spare parts shortage quantity estimation. Aircraft spare parts and warship spare parts are usually limited by time, space and some other aspects of constraints, for the problem of aviation equipment procurement decisions on spare parts inventory levels (Yoon \& Sohn, 2007), he developed a two stage model and combined the time-varying characteristics of procurement of spare parts to solve the problem. In order to solve the huge losses due to high cost of spare parts shortage, the allocation model (Costantino, Gravio \& Tronci, 2013) was proposed based on the optimal type of spare parts inventory management thoughts, considering the maintenance center repair ability combined with the system availability, and multi-level, variety of spare parts, multistage multiple constraints of spare parts. Regattieria, Gamberia, Gamberinib and Manzinia (2005) proposed an effective prediction method to solve predicting problem of fluctuating demand for aviation spares, which proved the independence of the spare parts demand fluctuations, both the test data and historical data were used in the algorithm analysis and results comparison. Lee, Chew, Teng and Chen (2008) proposed the simulation optimization method that was used to solve the problem of aviation spare parts distribution, developed a multi-objective evolutionary algorithm, which is concluded by many factors such as cost, spare parts satisfactory rate under the constraint of two level that can keep the spare parts inventory distribution planning. Moon, Hicks and Simpson (2012) solve the problem of naval vessel frequency and number of spare parts demand irregularity led to predict difficult problem, put forward using combination of historical data and predicted data, and combined with exponential smoothing method to reduce occurrence time of the errors in the forecast. Shuhuan, Yanqiao and Jiashan (2013) regarded spare parts and warehouse space as a total funding constraint, on the basis of equipment level decomposition structure, considering warship spare parts replacement ability and spare parts failure rate, on the basis of those factors to propose spare parts planning model which adopted the marginal analysis method. Smidt-Destombesa, Heijdenb and Hartenb (2009) propose a heuristic algorithm to solve the spare parts inventory problem, and the other problem regarding maintenance frequency and repair ability of combined optimization problem, METRIC improved model was applied to the spare parts inventory optimization research, it is concluded that the system availability was greatly improved and the cost planning is the optimal. One paper (Ramesh Reddy, Muni Reddy \& Mohana Reddy, 2012) has studied the inventory optimization problem of multiple items, both costs and other factor were considered in the study of storage space constraints, which is more closer to the actual situation for enterprise. 
In the field of cannibalization strategy research (Fisher, 1990) solved the problem of complex optimization problem of airline fleet maintenance system, using markov process to optimize maintenance spare parts in the system allocation, considering other factors including maintenance and human resource factors. (Shen, Qingmin \& Yingwu, 2013) adopted cannibalization mode in the two level maintenance supply system, solved the problem based on the principle of Dyna - METRIC model under the limited resource constraints of multichannel repairs and proposed spare parts inventory allocation of dynamic management model. Minzhi, Qingmin, Yingwu, PAolin and Shen (2012) has solved the problem in accordance with the characteristics of spare parts cannibalization, combining the theory of METRIC model and considering the availability to improve equipment system, and then determined the planning of the spare parts inventory.

All the above research are dealing with the problem of spares support planning, which make an analysis from different angles including the security level, various and multi-echelon spares, equipment storage space. But for all the research papers, there is not any paper has focused on the integrated factors for support problem such as support cost, emergency ability, maintenance capability, maintenance policy and some other factors which are in comprehensive consideration those. This paper improves the ability of supporting of equipment and modeling the warship carrying spare parts support system, adopting the cannibalization maintenance, lateral transshipment supply scheduling strategy, which was in consideration of the multiple factors to make the optimal equipment support scheme.

\section{Support Process Description and Modeling Assumption}

\subsection{Support Process Description}

When warships were carrying out mission at sea, obviously, the warship itself is a single echelon maintenance support department and the spare parts storage warehouse. When the malfunction of the navigation of warships happens, however, it is unlikely to deliver the failure equipment or failure items to maintenance department on land. We need to take strategy of voyage repair immediately to restore the equipment performance which usually adopts a method of replacing the failure item as soon as possible. Disassembled failure parts were transferred to the repair job shop, and the following step is to pass the successful repaired items to the warehouse as new ones to use. Spare parts line-replaceable unit (LRU) needs a process to show the relationship among supply, maintenance, repair and even the recycling of spares. The process is shown in Figure 1. 


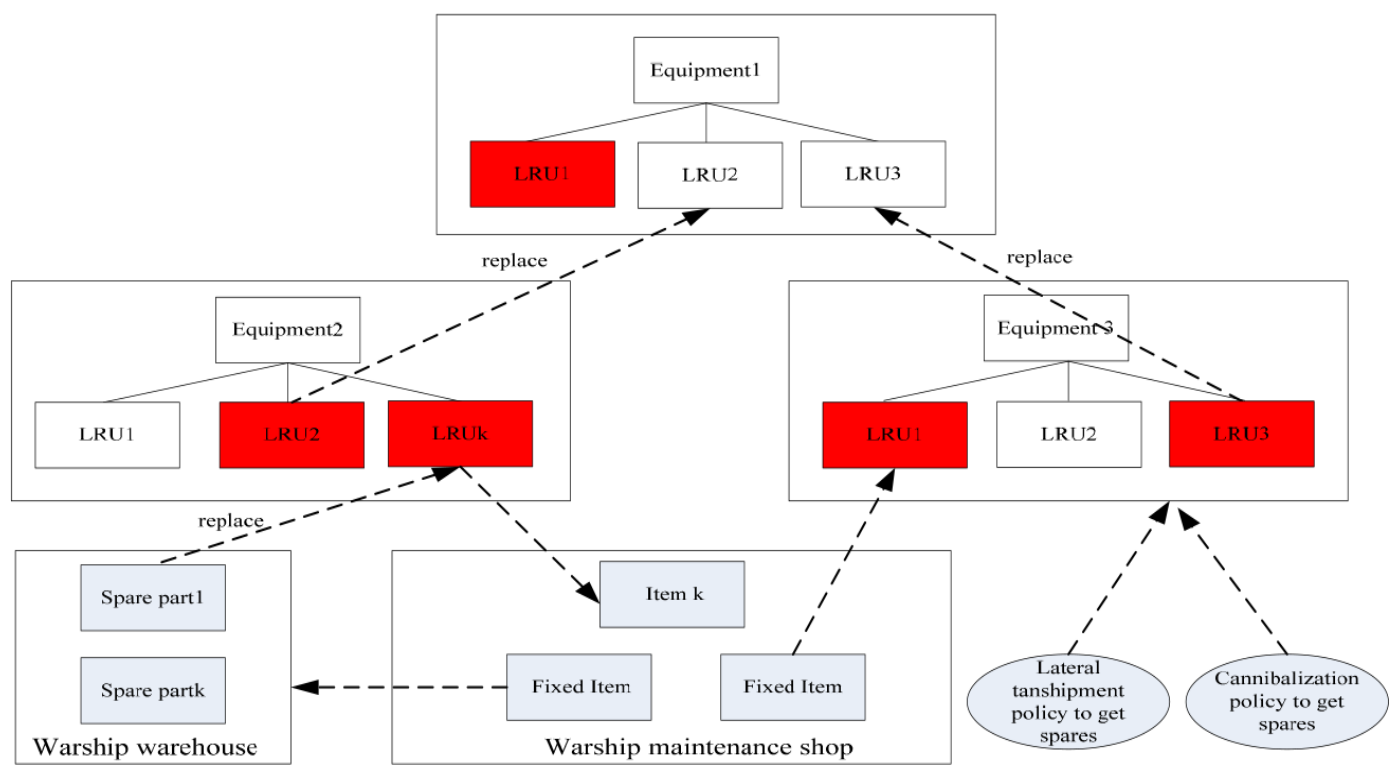

Figure 1. Maintenance process of failure item for warship spare parts support system

If equipment went out of order at times that will produce spare parts demand, new spare parts was used to replace the failure ones, if the failure ones can be repair successfully in repair job shop, which would be stored as new spare parts in the warehouse. If there is not enough LRU spare parts in warship warehouse, this kind of thing would be called a shortage. We can take two strategies to restore the operation condition at this time, first one is lateral transport supply strategy which could choose a nearby supply ship to transport the required LRU spare parts; the second one is to take strategy of cannibalization. Figure 2 can show the process from getting spare parts to repairing, supplying and recycle using and the perspective of management, these four relations describe the warship spare parts to ensure the feedback relationship between supply and demand processes. If maintenance needs spare parts which are inquired from warehouse with the information flow in the system; Spare parts warehouse will send a material flow to the equipment, while repair job shop could receive the failure items and take fixed items as new spare parts as material flow to warehouse; Spare parts move as the material flow in the system, but it is consumed between the supply and maintenance cycle, difference between spare parts supply and demand could be filled by lateral supply and cannibalization.

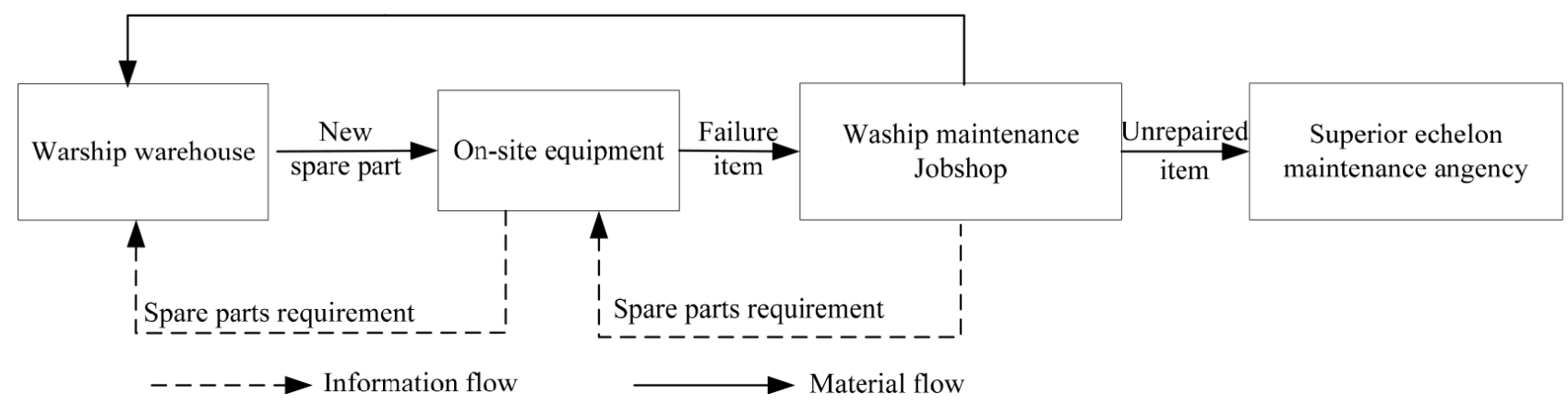

Figure 2. Feedback relationship of warship spare parts support process 


\subsection{Assumption}

To propose the model we need to make the following key assumptions:

(1) The warship job shop should repair all the failure items in accordance with the principle of first-in-first-out, regardless of considering the batch repair problems;

(2) The failure items are independent with each other, and equipment failure obeys the steady-state Poisson distribution;

(3) All the items installed on the equipment are repairable spare parts, and the items which are successfully fix can be regarded as new ones, the life span is the same with new spare parts;

(4) If some failure items cannot be repaired its malfunction in the ship repair shop, which were kept to repair in the superior maintenance department until the warship returned to the base, and those failure parts eventually fixed in the base maintenance department;

(5) If the warship equipment component fails, while the equipment should stop to wait for maintenance and failure recovery.

Hypothesis (1) sets the repair sequence of spare parts in the maintenance department, repair the batch of failure items will be limited by maintenance capacity constraints, which requires a lot of maintenance staff and tools, consequently, with limited ability of the warship repair job shop, it is reasonable to repair in accordance with the principle of first-in-first-out; Hypothesis (2) prescribes that the failure of items are mutual independence, otherwise we need to consider cascading failures that will increase the complexity of the problem, therefore, demand for spare parts could be generated according to the Poisson distribution, we can also follow the other distributions such as Weibull distribution, exponential distribution, other demand condition will be calculated in the following research; Hypothesis (3) considers the maintainability of spare parts, that is to say repairable spare parts have the value of using and carrying. The replacement itemed could be fixed and used as new ones. The life cycle of repaired parts are the same as the new ones; Hypothesis (4) provides the destination of those items which could not be fixed in warship repair job shop, those items will be send to the higher level maintenance department and repair successfully there; Hypothesis (5) provides that equipment downtime is subject to maintenance and spare parts supply condition. The complexity of the failure, difficulty in maintenance and shortage of spare parts will extend downtime of equipment. 


\section{System Dynamics Modeling of Warship Spare Parts Supply Support System}

\subsection{Causal Relationship of Carrying Spare Parts}

Warship carrying spare parts support process is a complex dynamic system, which has the characteristic of the traction demand. Consequently, demand of spare parts is of great importance to the system, there are some connection and causal relationship among the various factors that associated with the demand, which can be shown in Figure 3. The demand of spare parts has an impact on inventory of carrying spare parts and spares' supply-demand difference, if the supply is less than demand, spare parts supply and the difference would be negative, and then there should be having reduced inventory, which needs to solve the problem of supply and demand gap by adopting lateral supply scheduling strategy; If supply exceeds demand, the difference of spare parts supply is positive, there is no need to replenish spare parts.

Spare parts demand is mainly influenced by two factors, random failure rate and normal failure rate of spare parts, working environment of spare parts is so harsh that some of the spare parts will be in failure state easily, due to some factors such as temperature, humidity, coefficient of the device power off circulatory system could not keep in good condition, Consequently, spare parts are more prone to failure in storage state, replacement of the failure of parts or obsolete failure parts will decrease inventory level; Normal spare parts failure could replace by new parts and generate the demand for spare parts. Those two factors will have positive growth impact on the demand for spare parts. Lateral supply scheduling, consuming amount of spare parts and replenishment amount of spares will influence the level of inventory, spare parts reflux using can increase the inventory levels which is limited by warship repair shop maintenance capabilities, if the maintenance capability is stronger, the more available spare parts could repair successfully; If the difference between spare parts supply and demand is too large that there will be in short supply, lateral supply scheduling strategy is adopted to raise inventory level, after the supply ships receive the requested information, and then the necessary spare parts are carried to the receiving warship. 


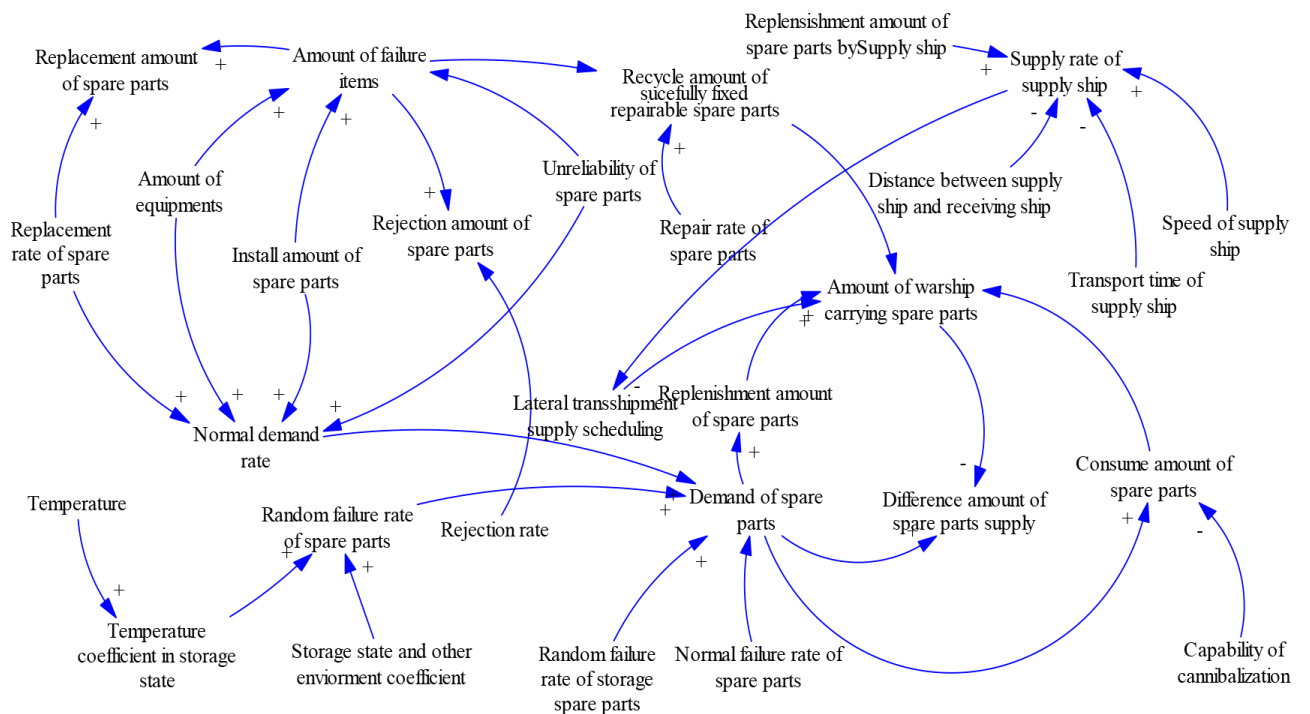

Figure 3. Causal relationship of warship spare parts support system

\subsection{System Flow Graph Model}

The system dynamics scheme model under multi-echelon need to describe the relationship among three variables including replenishment amount of spare parts, inventory of spare parts and demand of spare parts. The support system includes 9 level variables, 15 rate variables, some auxiliary variables and constants. Warship spare parts support system dynamics model is as illustrated in Figure 4.

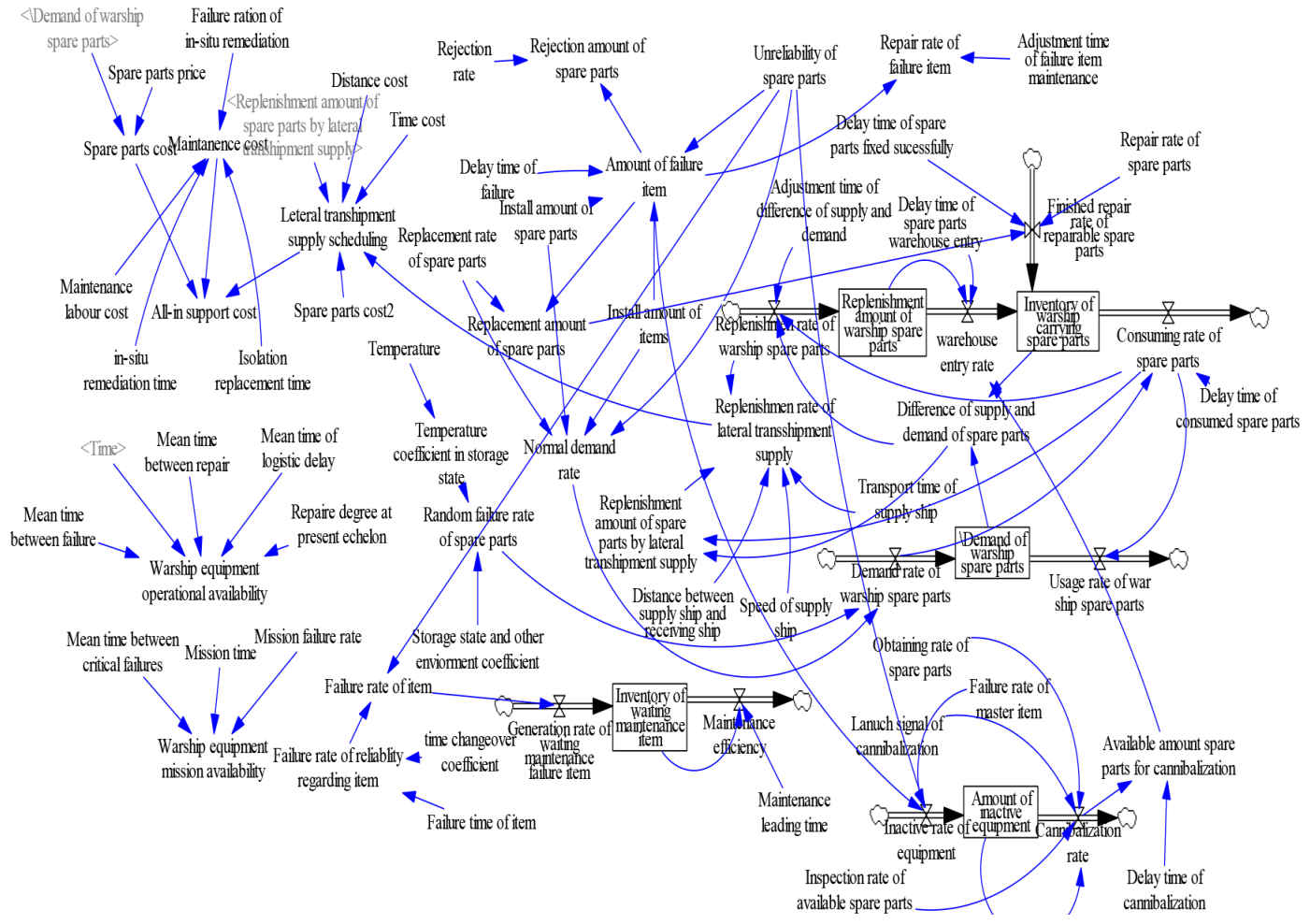

Figure 4. Warship spare parts support system dynamics model 
In order to express the equation of warship support process, we need to code some variable. The variable description and declaration are shown in Table 1.

\begin{tabular}{|c|c|c|}
\hline Variable name & Variable properties & Variable code \\
\hline Inventory of warship carrying spare parts & L & CSPI \\
\hline Replenishment amount of warship spare parts & L & WSPI \\
\hline Adjusting time of difference between spare parts supply and demand & $\mathrm{C}$ & ONS \\
\hline Replenishment rate of lateral transshipment supply & $\mathrm{R}$ & wspir \\
\hline Delay time of spare parts entry warehouse & $\mathrm{C}$ & $\mathrm{T} 1$ \\
\hline Demand of warship spare parts & $\mathrm{R}$ & wspdr \\
\hline Replenishment rate of lateral transshipment supply & $\mathrm{R}$ & iwspdr \\
\hline Warehouse entry rate & $\mathrm{R}$ & wsper \\
\hline Difference of spare parts supply and demand & A & SPDSD \\
\hline Usage rate of warship spare parts & $\mathrm{R}$ & wspur \\
\hline Inactive rate of equipment & $\mathrm{R}$ & edr \\
\hline Finished repair rate of repairable spare parts & $\mathrm{R}$ & rspsrr \\
\hline Delay time of consumed spare parts & $\mathrm{C}$ & $\mathrm{T} 2$ \\
\hline Replenishment amount of spare parts by lateral transshipment supply & A & LTIWISP \\
\hline Demand rate of warship spare parts & $\mathrm{R}$ & wspdr \\
\hline Speed of lateral transshipment supply ship & A & LTIWISP \\
\hline Amount of inactive equipment & $\mathrm{L}$ & EDAN \\
\hline Transport time of supply ship & A & T6 \\
\hline Cannibalization rate & $\mathrm{R}$ & $\mathrm{cmr}$ \\
\hline Temperature coefficient in storage state & A & SSTCE \\
\hline Available amount of spare parts for cannibalization & A & CMN \\
\hline Storage state and other environment coefficient & $\mathrm{C}$ & SSOCE \\
\hline Mean time between failure & A & MTBF \\
\hline Failure time of item & A & TBF \\
\hline Delay time of warship maintenance & $\mathrm{C}$ & T3 \\
\hline Normal demand rate & A & NDR \\
\hline Inventory of waiting maintenance item & $\mathrm{L}$ & WRI \\
\hline Replacement amount of spare parts & A & SPRN \\
\hline Generation rate of waiting maintenance failure item & $\mathrm{R}$ & wtfpr \\
\hline Delay time of spare parts fixed successfully & $\mathrm{C}$ & T4 \\
\hline Maintenance efficiency & $\mathrm{R}$ & me \\
\hline Amount of failure item & A & FIN \\
\hline Rejection rate & $\mathrm{C}$ & DR \\
\hline Repair rate of failure item & A & FIRR \\
\hline Adjusting time of failure item maintenance & C & FIRRT \\
\hline Rejection amount of spare parts & A & DSPN \\
\hline Amount of equipment & C & $\mathrm{MN}$ \\
\hline Unreliability of spare parts & $\mathrm{C}$ & $1-R(t)$ \\
\hline Install amount of spare parts & $\mathrm{C}$ & IIN \\
\hline
\end{tabular}

Table 1. Variable definition and code 


\subsection{Instruction for Equations}

\subsubsection{Equations for Spare Parts Replenishment Modular}

The two ways of replenishing spare parts are lateral transshipment supply and recycle using of repaired spare parts respectively. Replenishment rate of lateral transshipment supply is subject to difference between supply and demand, as while as spare parts consumption rate these dual constraints, when supply exceeds demand, there is no need to perform resupply missions, along with spare parts inventory levels will continue to decrease, when supply is less than demand that inventory cannot satisfy the occurrence of maintenance needs that requires to perform resupply missions to replenish inventories, spare parts consumption rate must be greater than the previous time interval of that, the difference between supply and demand will be relieved. Lateral supply spare parts strategy is equivalent to the ordering process, when the inventory cannot meet the maintenance requirements, lateral supply ships will provide the equivalent amount of spare parts to meet the consumption supply spare parts. The process can be expressed as the following equations.

$$
\begin{gathered}
\operatorname{WSPI}(t+1)=\operatorname{WSPI}(t)+\int_{0}^{t}[\mathrm{wspir}(t)-w \operatorname{wper}(t)] d t \\
\operatorname{wspir}(t)=\left\{\begin{array}{l}
0, \operatorname{OSPDSD}(t) \geq 0 \\
\operatorname{spcr}(t)+\frac{\mathrm{WSPD}(\mathrm{t})-\mathrm{CSPI}(\mathrm{t})}{\mathrm{T} 1}, \operatorname{SPDSD}(t)>0
\end{array}\right. \\
\text { wsper }(t)=\operatorname{WSPI}(t-T 1) \\
\operatorname{SPDSD}(\mathrm{t})=\operatorname{WSPD}(\mathrm{t})-\mathrm{CSPI}(\mathrm{t}) \\
\operatorname{CSPI}(t+1)=\operatorname{CSPI}(t)+\int_{0}^{t}[\mathrm{wsper}(t)-\operatorname{spcr}(t)] d t \\
i w \operatorname{spdr}(\mathrm{t})=\frac{\mathrm{wspir}(\mathrm{t}-T 6)+w \operatorname{wpir}(\mathrm{t}-\mathrm{T} 6)}{\operatorname{LTIWISP}(\mathrm{t}-\mathrm{T} 6)} * \operatorname{LTISPD}(\mathrm{t}-\mathrm{T} 6)
\end{gathered}
$$

\subsubsection{Equations for Spare Parts Demand Modular}

Spare parts demand is the pulling power of delivering the material and information flow, which is subject to demand of maintenance. Consequently, consuming rate of spare parts will be limited by demand rate of spare parts, when there is lack of spare parts so that the remaining inventory cannot meet the demand, spare parts consumption rate is spare parts inventory levels currently, difference between spare parts supply and demand will be meet by the spare parts which are provided by lateral supply strategy. Spare demand is influenced by equipment reliability, some factors such as the mean time between failure of equipment, uptime and downtime of equipment, and spare parts usage rate. There will be multiple proportional 
relationships due to those factors. Of course, some precise spare parts working in maritime whose operations environment is harsh, temperature, humidity, device power-off coefficient of the circulatory system, environmental factors such as chemical $\mathrm{pH}$ cannot guarantee in stable condition, spare parts in warehouse will be in failure easily. Those consumed spare parts can be taken as the equivalent of failure demand, adding with the regular consumption of spare parts. The equations are shown as follow:

$$
\begin{gathered}
\operatorname{WSPD}(\mathrm{t}+1)=\operatorname{WSPD}(\mathrm{t})+\int_{0}^{t}[\operatorname{wspdr}(\mathrm{t})-\text { wspur }(\mathrm{t})] \\
\operatorname{wspdr}(\mathrm{t})=\operatorname{spur}(\mathrm{t}) \\
\operatorname{wspur}(\mathrm{t})=\operatorname{SPRFR}(\mathrm{t})+\operatorname{NDR}(\mathrm{t}) \\
\operatorname{IFR}(\mathrm{t})=\operatorname{MTBF}(\mathrm{t}) * \operatorname{ISCE}(\mathrm{t}) \\
\operatorname{MTBF}(t)=\frac{\text { totaluptime }(t)-\operatorname{total} \text { downtime }(t)}{\text { number of breakdowns }(t)} \\
\text { totaluptime }(t)=\operatorname{lookup}(\operatorname{TIME}) \\
\text { totaldowntime }(t)=\operatorname{lookup}(\operatorname{TIME})
\end{gathered}
$$

\subsubsection{Equations for Maintenance Modular}

To be exact, warship maintenance work will fix the failure item and recover the function of this component. The finished repair item could be used as new spare parts and this process is some kind of reverse logistics. The restraining factors of spare parts inventory including replenishment rate of lateral transshipment supply and finished amount of fixed spare parts, when the amount of fixed spare parts increase, the inventory level of spare parts will rise too. If the remaining spare parts can meet the demand, we could reduce the amount of spare parts provided by lateral transshipment supply strategy. Restoration on the number of spare parts and reuse of spare parts supply and demand for the difference plays a positive regulatory role in the system. Failure items include conventional failure parts and some random failures occurrence in storage state. Delivery the failure ones to repair job shop and the successfully fixed parts to warehouse. Those damage ones will be sent to higher level maintenance station. The rejection amount of spare parts will be regard as a process of consuming as used. Maintenance module can be expressed as the following equations. 


$$
\begin{gathered}
\text { wspdr }(\mathrm{t})=\operatorname{SPRFR}(\mathrm{t})+\mathrm{NDR}(\mathrm{t}) \\
\operatorname{SPRFR}(\mathrm{t})=\operatorname{SSOCE}(\mathrm{t})+\operatorname{SSTCE}(\mathrm{t}) \\
\operatorname{NDR}(\mathrm{t})=\operatorname{SPRR}(\mathrm{t}) * \mathrm{MN}(\mathrm{t}) * \operatorname{IIN}(\mathrm{t}) *(1-\mathrm{R}(\mathrm{t})) \\
\operatorname{EDTCN}(\mathrm{t}+1)=\operatorname{EDTCN}(\mathrm{t})+\int_{0}^{t}[\operatorname{edr}(\mathrm{t})-\operatorname{cmr}(\mathrm{t})] \\
\operatorname{mer}(\mathrm{t})=\mathrm{WRI}(\mathrm{t}-\mathrm{T} 5) \\
\text { wfipr }(\mathrm{t})=\operatorname{IFR}(\mathrm{t}) \\
\operatorname{IFR}(\mathrm{t})=1-\mathrm{R}(\mathrm{t}) \\
\operatorname{cmr}(\mathrm{t})=\frac{[\operatorname{EDTCN}(\mathrm{t})-\mathrm{CMN}(\mathrm{t})]}{T 7} \\
F I N(\mathrm{t})=\frac{[1-\mathrm{R}(\mathrm{t})] * \mathrm{MN}(\mathrm{t}) * \operatorname{IIN}(\mathrm{t})}{T 5}
\end{gathered}
$$

\section{Availability and Support Cost Calculation Model}

It is necessary to say that it is a matter of great important to balancing the relationship among the three factors including operational readiness and mission success and spare parts planning, consequently, we can use mission availability and operational availability as an index to judge spares support policy. Operational availability is regarded as a significant target to measure the mission enduring ability and service quality for warship equipment, whose advantage is to integrate reliability and maintainability and indemnificatory in mission executing aspect. We have to talk about that a variety of availability which include inherent availability and operational availability and achieved availability. Those indexes can be measurement of evaluating work state of equipment when they are needed to use. The best choice of selecting an index to evaluate operational readiness is to operational availability. It is indicated that operational availability can measure the proportion of actual work time and calendar working hours of warship in the whole life cycle, so the quantitative measure to make the research object,

$$
A_{0}=\frac{M T B F}{M T B F+M T T R+M L D T}
$$

MTBF is mean time between failure that has something to do with failure rate of equipment, MTTR is the mean time between repair which has a bearing on the cycle time of equipment if the failure is cleared, MLDT is the mean time of logistic delay, that is, the mean time of waiting spare parts and maintenance and material needed by repair. The equipment has two state of working, first one is downtime maintenance state and second one is normal running state. While the state of equipment is transfer from one to the other, when the equipment is out of 
order, the condition is changing from running state to the first state. The equipment can be restored the running state by maintenance.

The mission availability is used to describe the operational availability of warship equipment during mission carried out at sea. Regardless of preventive maintenance effect in accordance with the angle of mission carried out at sea, for this reason the mission availability of warship equipment can be expressed roughly as

$$
\begin{aligned}
A_{M}=1 & -\frac{\text { MART }}{\text { MTTCF }+ \text { MART }}-\frac{\text { PMdowntime }}{\text { Missiontime }} \\
& -P_{f}\left(1-\frac{\text { MTTCFnrf }}{\text { Missiontime }}\right)
\end{aligned}
$$

MART present the mean value of corrective repair time. Besides, MTTCF is the mean time between critical failures of equipment during mission time at sea. Missiontime is defined as the carried out mission time at sea. PMdowntime is used to describe the total preventive maintenance downtime for mission, TBMF is time between critical failures that cannot be repairable at sea which will cause the mission failure. $M T T C F_{n i f}$ is the mission failed time which is caused by the unrepairable failure item during the mission at sea. In the specific cases, it is supposed that the warship equipment implements $\mathrm{N}$ missions and the successful mission is $N_{s}$. Some critical failures will lead to the mission stop and some failures must be repaired immediately, it is supposed that the support delay time length is zero. The corrective repairs is represent by $a$ in the some mission of the all the successful missions. The operation availability is defined as

$$
A_{i}=\frac{\text { Missiontime }-\sum_{x=1}^{a} A R T_{i x}-P M \text { downtime }_{i}}{\text { Missiontime }}
$$

The total number of failed mission can be expressed as $N-N_{s}$, which means the all-in numbers of mission subtract the numbers of successful mission. When the maintenance time is not taken into account that the availability of equipment can be expressed as

$$
A_{j}=\frac{T_{B M F_{j}}-\sum_{y=1}^{b} A R T_{j y}-\text { PMdowntime }_{j}}{\text { Missiontime }}
$$

Defining $P_{s}$ as the mission success rate, then $P_{s}=N_{s} / N$. Define $P_{f}$ as the mission failure rate, then $P_{f}=1-N_{s} / N$. The mission availability of warship equipment can be expressed as following:

$$
\begin{aligned}
& A_{M}=\frac{N_{s}}{N}+\frac{\sum_{j=1}^{N-N_{s}} \operatorname{TBMF}_{j}}{N \cdot \text { Missiontime }}-\frac{\sum_{i=1}^{N_{s}} \text { PMdowntime }_{i}}{N \cdot \text { Missiontime }} \\
& -\frac{\sum_{j=1}^{N-N_{s}} \text { PMdowntime }_{j}}{N \cdot \sum_{i=1} \sum_{x=1}^{N_{s}} \sum_{x \rightarrow 1}^{a} A R T_{i x}+\sum_{j=1}^{N-N_{s}} \sum_{y=1}^{b} A R T_{j y}}
\end{aligned}
$$


The MTBMF in the formula is defined as the mean time between critical failures repairable at sea. The critical failures will lead to the warship equipment fail to carry out the mission at sea, during the task, the total preventive maintenance down time compared with all-in the task of time is very short, consequently, we suppose if each task time length of preventive maintenance down time are the same.

$$
\begin{aligned}
A_{M}= & \frac{N_{s}}{N}+\frac{\sum_{j=1}^{N-N_{s}} T B M F_{j}}{N \cdot \text { Missiontime }}=\frac{N_{s}}{N}+\frac{\left(N-N_{s}\right) \frac{\sum_{j=1}^{N-N_{s}} T B M F_{j}}{N-N_{s}}}{N \cdot \text { Missiontime }} \\
& =1-p_{f}+p_{f} \frac{\text { MTBMF }}{\text { Missiontime }} \\
& =1-p_{f}\left(1-\frac{\text { MTBMF }}{\text { Missiontime }}\right)
\end{aligned}
$$

\section{Case Study}

Spare parts supply system of warship which is navigation at sea was regarded as research object, there are 24 equipment with the same model, each of them has installed 8 items, system operation cycle is 100 weeks, simulation step is 1 , delay time of spare parts warehouse entry is 0.5 week and adjustment time of difference of supply and demand is 1 week, delay time of consumed spare parts is 2 weeks, delay time of failure is 0.1 week, delay time of cannibalization is 0.2 week and maintenance leading time is 1 week, delay time of spare parts fixed successfully is 1.5 week, Storage state and other environment coefficient includes $1.16,4.8,2.3,0.0035$, rejection rate is 0.21 and replacement rate of spare parts is 0.7 , repair rate of spare parts is 0.81 , failure time of item is 1200 hours, time changeover coefficient is 12 , temperature is random number between $[5,40]$, transport time of lateral transshipment supply is 3 weeks, spare parts by lateral transshipment supply, speed of supply ship is 210 kilometers per hour. The simulation model were run continuously for at least 10 times, any time was picked up from those results. The inventory of warship carrying spare parts is as shown in Figure 5, there is a fluctuation character in growth, demand of warship spare parts is as shown in Figure 6, replenishment amount of warship spare parts is as shown in Figure 7, and difference of supply and demand of spare parts is as shown in Figure 8. 


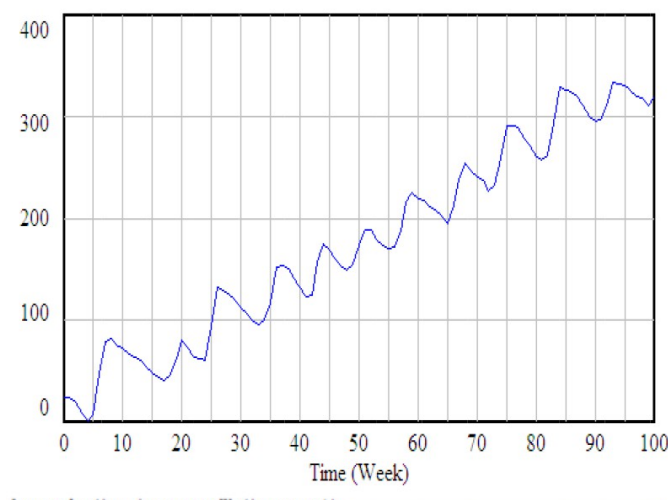

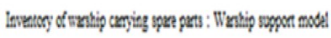

Figure 5. Inventory of warship carrying spare parts

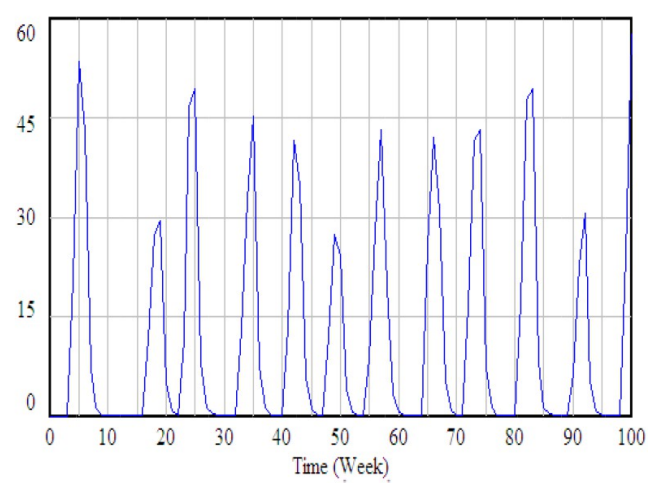

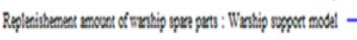

Figure 7. Replenishement amount of spare parts

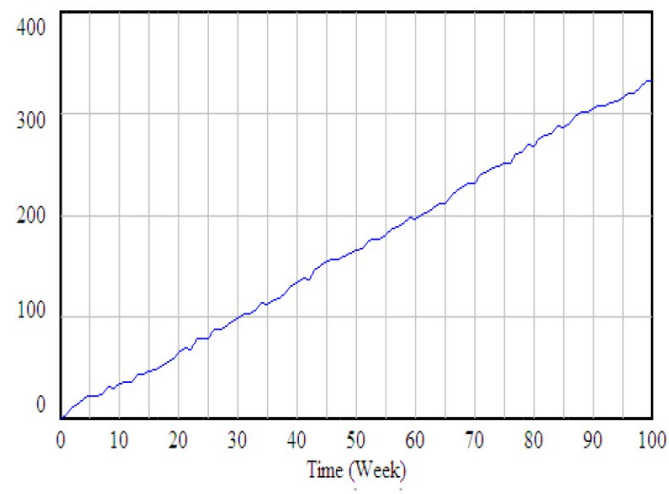

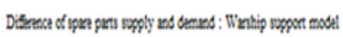

Figure 6. Demand of warship spare parts

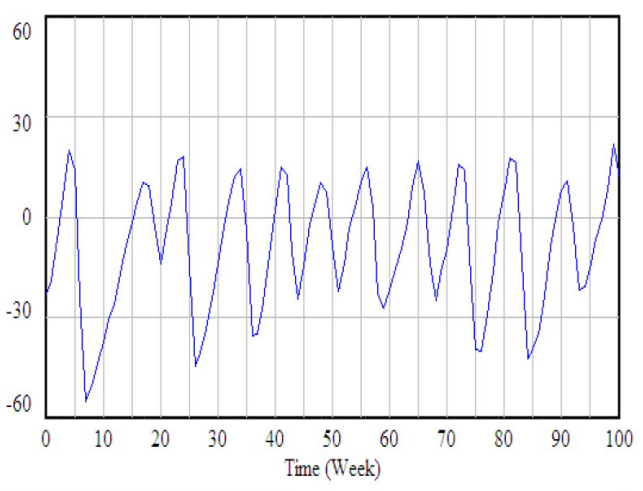

Figure 8. Difference of spare parts supply and demand

There is fluctuation characteristic in each variable in the warship support process, fluctuation peak correspond the regulation of difference between spare parts supply and demand, we can make a conclusion from Figure 8 that when the spare parts supply and demand difference peak is less than zero, we need to take the lateral supply scheduling strategy to supplement gap. Simulation result of finished repair parts is shown in Figure 9, this method can also serve as a way to supplement the gap between demand and supply of spare parts, with the increase in the number of complete failure repair can continue to use the number of reflux parts also increases, thus the finished repair rate also appears growth trend, the simulation result of replenishment rate of lateral supply strategy is shown in Figure 10, whose trend vary with the change of spare parts supply and demand difference gap. 


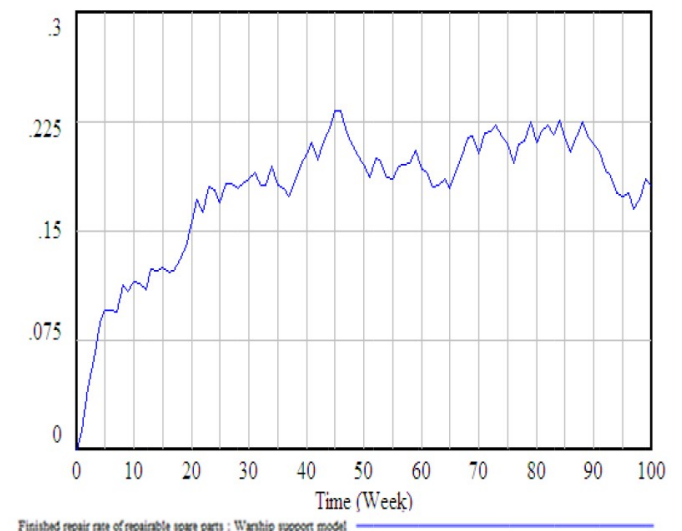

Figure 9. Finised repair rate of repairable spare parts

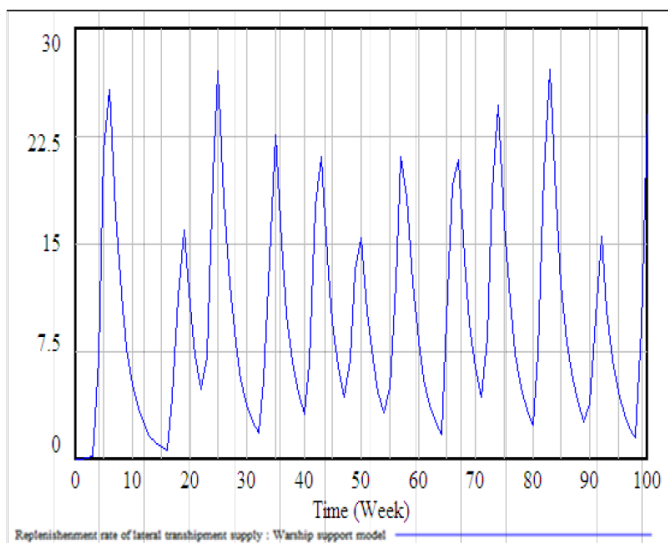

Figure 10. Replenishement rate of lateral supply

Cannibalization is a way of repairing with the limited resources, due to some factors affected by the repair ability and repair time constraints, and then considers using this method is economical and convenient. Therefore, the first model takes lateral supply strategy only, think about adjusting factors related to lateral supply scheduling strategy to set reasonable inventory and achieve higher equipment availability. When the system considered only by lateral supply scheduling strategy to fill the gap between spare parts supply and demand, the all-in cost and operation availability data could be calculated in the system, and mission availability changes from a minimum value of 0.3253 to the maximum value of 0.9782 , mean value of mission availability is 0.6475 . Adjusting the lateral supply scheduling cost in time to reduce the all-in cost and making security factors adjustment strategy as follows can bring down the support cost:

Strategy 1: Speed of supply ship $=300$ kilometers per hour, Failure ration of in-situ remediation $=0.2$, in-situ remediation time $=100$ hours, Mean time of logistic delay $=1.5$ weeks, Repair rate of spare parts $=0.82$.

Strategy 2: Speed of supply ship $=350$ kilometers per hour, Failure ration of in-situ remediation $=0.15$, in-situ remediation time $=90$ hours, Mean time of logistic delay $=1.2$ weeks, Repair rate of spare parts $=0.83$.

There are two factors which have greater impact on support cost including $C_{M}$ the cost of maintenance and $C_{L}$ lateral supply scheduling costs, maintenance costs in the proportion of the relevant parameters in situ repair failure will affect the change of maintenance cost, the significant factors of horizontal supply cost is the spare parts cost and time cost, as spare parts recovery rate increased the repair parts recycling will increase, which can buffer the difference gap between spare parts supply and demand, moreover, the amount of spare parts by lateral supply scheduling is reduced; If we improve the supply ship speed and shortens transverse scheduling waiting time, reduced time and cost can be bring down the lateral supply 
scheduling cost. The support cost and the warship operational availability simulation results are shown in Figure 11 and Figure 12, which can be seen that according to the analysis of adjustment, strategy 2 achieved better effect.

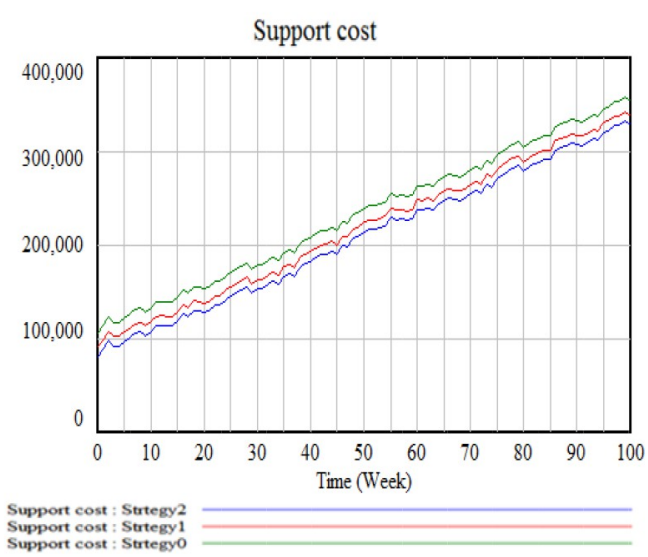

Figure 11. Warship Support cost

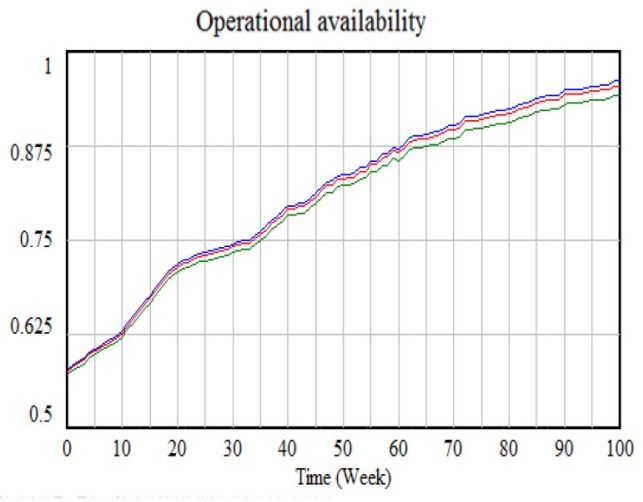

Operational avalability : Strtegy 2
Operational avalabbility : Strtegy1

Figure 12. Operational availability of warship equipment(a)

The cannibalization strategy was adopted to resume operation as much as possible of the equipment without enough maintenance resource; the crux parameter should have some adjustment to obtain the optimal spare parts support strategy. But cannibalization should be adopted under the condition that disassembly time is no longer than maintenance time and the maintenance cost is less than buying brand new equipment. At this case the cannibalization can get the expectation effect. Consequently, cannibalization regarding factors in the support system is shown as follows:

Strategy 3: Obtaining rate of spare parts $=0.8$, Inspection rate of available spare parts $=0.8$, Delay time of cannibalization $=20$ hours, Speed of supply ship $=300$ kilometers per hour, Failure ration of in-situ remediation $=0.2$, in-situ remediation time $=100$ hours, Mean time of logistic delay $=1.5$ weeks, Repair rate of spare parts $=0.82$.

Strategy 4: Obtaining rate of spare parts $=0.6$, Inspection rate of available spare parts $=0.9$, Delay time of cannibalization $=18$ hours, Speed of supply ship $=350$ kilometers per hour, Failure ration of in-situ remediation $=0.15$, in-situ remediation time $=90$ hours, Mean time of logistic delay $=1.2$ weeks, Repair rate of spare parts $=0.83$. 


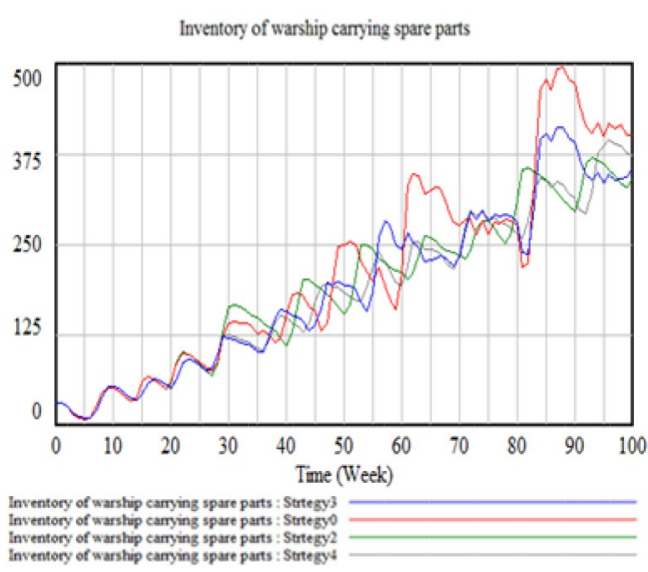

Figure 13. Inventory of warship carrying spare parts

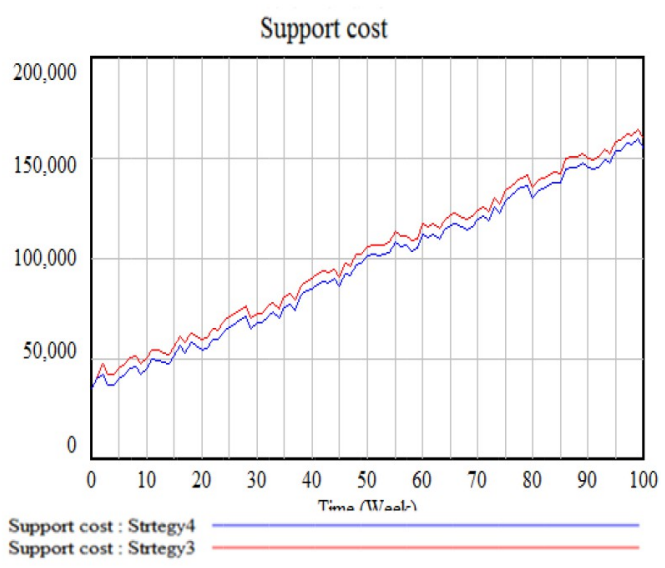

Figure 15. Warship spare parts all-in support cost

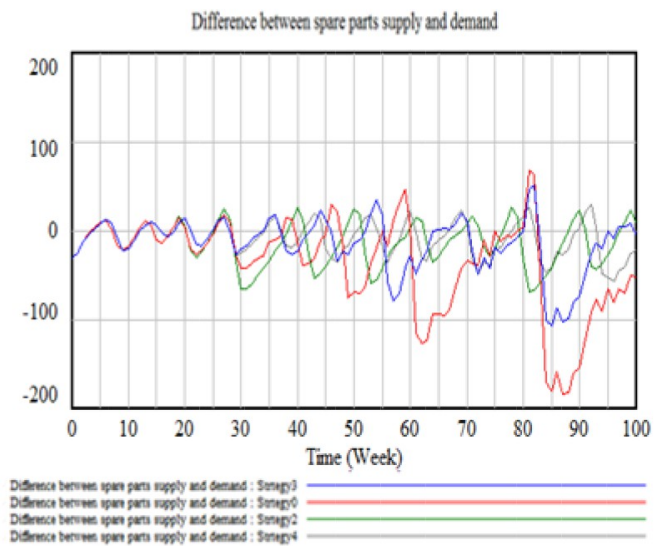

Figure 14.Difference between spare parts supply and demand

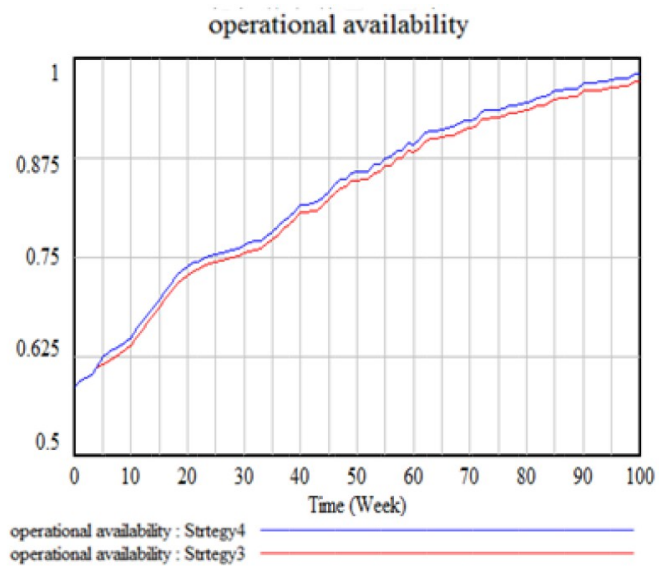

Figure 16. Warship operational availability result(b)

Lateral transshipment supply strategy and cannibalization were adopted in the support system at the same time, which needs to be considered that when should the support system launch cannibalization strategy and which kind of situation the system will reach. We can get a conclusion from the simulation results that obtaining rate of spare parts is no more than six. The cannibalization should be launched at this kind of situation which can obtain satisfactory support effects for the system. The results of strategy 4 can be shown in Figure 13 and 14, which can perceive the minimum inventory and the effect of minimum inventory fluctuation is not obvious under this strategy. Moreover, this strategy can bring down the amount of spare parts getting from other external channel and reduce the all-in support cost. As shown in the Figure 13 and 14, we can get the comparison results among four strategies. The strategy 4 could be regarded as the optimal selection within the specific limits which is also getting the best support effect. As you can see from Figure 15 and 16, the effect of strategy 4 is superior to strategy 3 in support cost and equipment operational availability respect. The specific data can be shown in Table 2. 


\begin{tabular}{|c|c|c|c|c|c|c|}
\hline Operation cycle & Plan0 & Plan3 & Plan4 & A0 & A3 & A4 \\
\hline 10 & 45282 & 50271 & 50118 & 0.637412 & 0.638952 & 0.647353 \\
\hline 20 & 55391 & 52300 & 50132 & 0.707051 & 0.736059 & 0.737051 \\
\hline 30 & 77458 & 65654 & 63471 & 0.752312 & 0.762762 & 0.763992 \\
\hline 40 & 94583 & 89482 & 84431 & 0.795201 & 0.804328 & 0.815229 \\
\hline 50 & 106888 & 105732 & 100187 & 0.83992 & 0.84508 & 0.85612 \\
\hline 60 & 117109 & 114149 & 112181 & 0.870221 & 0.889670 & 0.890701 \\
\hline 70 & 129086 & 124086 & 119540 & 0.901632 & 0.921632 & 0.921632 \\
\hline 80 & 139207 & 135782 & 130622 & 0.934001 & 0.944001 & 0.944001 \\
\hline 90 & 149943 & 149843 & 144962 & 0.958875 & 0.968875 & 0.968875 \\
\hline 100 & 164675 & 159331 & 154129 & 0.973056 & 0.983056 & 0.983056 \\
\hline
\end{tabular}

Table 2. All-in support cost and operational availability

The simulation result of availability and all-in support cost is as shown in Figure 17; we can adjust the strategy in accordance with regulation of the dynamics behaviors for warship equipment support system. We can also give the specific control interval for the support strategy through the above model.

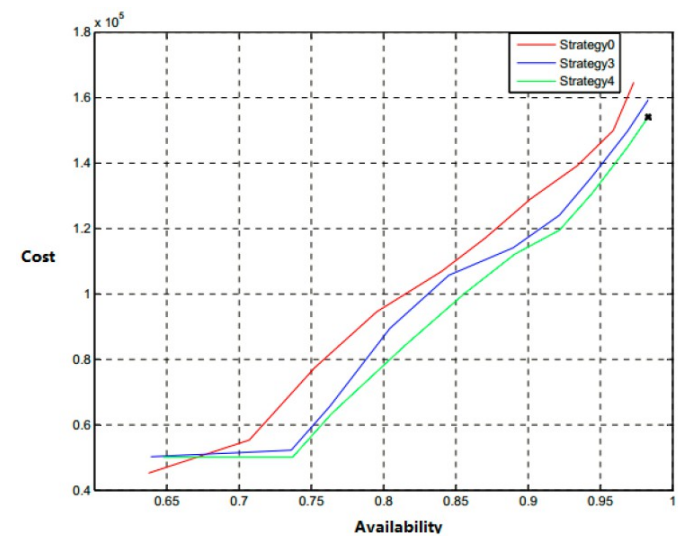

Figure 17. Results of availability and all-in support cost 


\section{Conclusion}

In this paper, we study an extension optimization problem of spare parts support for warship at sea. Moreover, we analyze the warship support problem under two types of strategies including lateral transshipment supply and cannibalization. The proposed model used system dynamics theory and was looked at from this point of view that can improve the support ability of warship. Therefore, it may be briefly summed up as follows: (1) Assuming that the amount of carrying spare parts for warship cannot meet the maintenance demand, we will adopt lateral transshipment strategy to replenish the needed spare parts by supply-ship. We developed the dynamics support planning model with system dynamics approach, considering many crux factors on support cost, maintenance ability, equipment operational availability and mission availability. The resource allocation and optimization strategy were designed in accordance with those factors. (2) We optimize the model under the condition that with no sufficient resource and resource of lateral transshipment supply cannot satisfy the needs of spare parts, then the support planning was designed in the light of this condition. Get the most optimal and valid planning by comparing the simulation results of different strategy among multi-strategy of lateral transshipment supply scheduling. After pondering this optimal problem with simulation method, I have finally reached the conclusion that considering some constraint factors of maintenance ability, support cost, equipment operational availability and mission availability, moreover, analyze the feedback relationship among many factors to find some of them have impact on supply and demand for spare parts. The proposed allocation planning can bring down the support cost efficiently and obtain the control of higher setting for both equipment operational availability and mission availability. In the actual condition, there will be some other emergency and sudden factors which could have some impact on the demand of warship spare parts. How to solve the problem of emergency condition support will be considered in the follow-up research.

\section{Acknowledgements}

The authors wish to acknowledge the National Natural Science Foundation of China, under the grant number 71231001. 


\section{References}

Costantino, F., Gravio, G., \& Tronci, M. (2013). Multi-echelon, multi-indenture spare parts inventory control subject to system availability and budget constraints. Reliability Engineering \& System Safety, 119, 95-101. http://dx.doi.org/10.1016/j.ress.2013.05.006

Fisher, W.W. (1990). Markov process modeling of a maintenance system with spares, repair, cannibalization and manpower constraints. Mathematical and Computer Modeling, 13(7), 119-125. http://dx.doi.org/10.1016/0895-7177(90)90134-9

Hillestad, R.J. (1982). Dyna-METRIC: dynamic multi-echelon technique for recoverable item control. Working Paper. Santa Monica, Calif: RAND Corpation. R-2785-AF.

Lee, L.H., Chew, E.P., Teng, S., \& Chen, Y. (2008). Multi-objective simulation-based evolutionary algorithm for an aircraft spare parts allocation problem. European Journal of Operational Research, 189(2), 476-491. http://dx.doi.org/10.1016/j.ejor.2007.05.036

Minzhi, R., Qingmin, L., Yingwu, P., Aolin, H., \& Shen, W. (2012). Evaluation of Equipment System Availability for Multi-echelon Maintenance Supply with Cannibalization. Acta Aeronautica et Astronautica Sinica, 4, 658-665. http://dx.doi.org/10.3969/j.issn.101-506X.2012.06.18

Moon, S., Hicks, C., \& Simpson, A. (2012). The development of a hierarchical forecasting method for predicting spare parts demand in the South Korean Navy-A case study International. Journal of Production Economics. 140(2), 794-802.

http://dx.doi.org/10.1016/j.ijpe.2012.02.012

Muckstadt, J.A. (1973). A model for a Multi-Item, Multi- echelon, Multi-indenture inventory system. Management Science, 20(4), 472-481. http://dx.doi.org/10.1287/mnsc.20.4.472

Ramesh Reddy, K., Muni Reddy, C.N., \& Mohana Reddy, B.C. (2012). Optimization of a Multi Item Inventory Problem with Multiple Constraints using Kuhn-tucker Conditions. International Journal of Applied Engineering Research, 7(5), 503-513.

Regattieria, A., Gamberia, M., Gamberinib, R., \& Manzinia, R. (2005). Managing lumpy demand for aircraft spare parts. Journal of Air Transport Management, 11(6), 426-431. http://dx.doi.org/10.1016/j.jairtraman.2005.06.003

Shen, W., Qingmin, L., \& Yingwu, P. (2013). Dynamic Management Model of Two-echelon Maintenance and Supply System for Spare Parts with Cannibalization. Acta Aeronautica et Astronautica Sinica, 34(6), 1326-1335. http://dx.doi.org/10.7527/S1000-6893.2013.0158

Sherbrooke, C.C. (1968). METRIC: A Multi-Echelon Techniques for Recoverable Item Control. Operation Research, 16(1), 122-141. http://www.rand.org/pubs/research_memoranda/RM5078 
Sherbrooke, C.C. (1986). VARI-metric: improved approximation for multi-indenture, multi-echelon availability models. Operation Research, 34(2), 311-319.

http://dx.doi.org/10.1287/opre.34.2.311

Shuhuan, W., Yanqiao, C., \& Jiashan, J. (2013). Warship spare parts allotment optimization method under space and cost constraints. Systems Engineering and Electronics, 35(12), 2540-2544. http://dx.doi.org/10.3969/j.issn.101-506X.2013.12.16

Smidt-Destombesa, K.S. de, Heijdenb, M.C. van der, \& Hartenb, A. van (2009). Joint optimization of spare part inventory, maintenance frequency and repair capacity for k-out-of-N systems. International Journal of Production Economics, 118(1), 260-268.

http://dx.doi.org/10.1016/j.ijpe.2008.08.058

Yoon, K.B., \& Sohn, S.Y. (2007). Finding the optimal CSP inventory level for multi-echelon system in Air Force using random effects regression model. European Journal of Operational Research, 180(3), 1076-1085. http://dx.doi.org/10.1016/j.ejor.2006.05.006

Journal of Industrial Engineering and Management, 2015 (www.jiem.org)

Article's contents are provided on a Attribution-Non Commercial 3.0 Creative commons license. Readers are allowed to copy, distribute and communicate article's contents, provided the author's and Journal of Industrial Engineering and Management's names are included. It must not be used for commercial purposes. To see the complete license contents, please visit http://creativecommons.org/licenses/by-nc/3.0/. 